\title{
Creation of an Undergraduate Engineering Laboratory with Minimal Fund- ing
}

\section{Dr. Amanie N. Abdelmessih, California Baptist University}

Before joining California Baptist University fall 2013, Dr. Abdelmessih taught in several universities, starting with Northrop University at the beginning of her career, and spent the last 16 years at Saint Martin's University, where she was the director of the Thermal Engineering Laboratory, which she founded and developed. She led the efforts to start the Master of Mechanical Engineering program, which started fall 2012 at Saint Martin's University. She developed and taught these courses: Thermal Design of Heat Exchangers; Heating, Ventilating, and Air Conditioning; Energy Systems; Computational Heat Transfer \& Thermal Modeling; Heat Transfer in Electronics and Micro-electronic Packaging; Solar Thermal Engineering; and Heat Transfer and laboratory. She also enjoyed teaching Thermodynamics I, II. In addition to her teaching experience Dr. Abdelmessih worked several years in industry. She performed research at NASA Dryden and Marshall Space Flight Research Centers, Argonne National Laboratory, and Pacific Northwest National Laboratory, receiving five certificates of recognition for her research contributions at NASA. She received the 2001 Outstanding Faculty Award from the Monks of Saint Martin's Abbey, the 2005 Academic Engineer of the Year from Puget Sound Engineering Council, Washington State, and the 2009 Distinguished Engineering Educator from the National Society of Women Engineers. Dr. Abdelmessih is a member of ASME, AIChE, ASHRAE, SWE, and ASEE; and several honor societies: the Society of Fellows, Omega Chi Epsilon, and Pi Tau Sigma. She is nationally and internationally active with ASME, she served numerous times as track organizer for the K-16 Heat Transfer in Electronic Equipment, at the Heat Transfer Conferences, and chaired numerous sessions during conferences. She reviews numerous articles for refereed Journals and Conferences. Dr. Abdelmessih's areas of research are mixed convection, conduction, heat exchangers, high temperature calibrations, drying in the paper industry, and absorption refrigeration. She has over 40 publications. 


\title{
Creation of Undergraduate Engineering Laboratory with
}

\section{Minimal Funding}

\begin{abstract}
Founding of new engineering laboratories requires large funding. Small liberal arts teaching universities, usually have limited funds particularly for engineering programs. This article details how a thermal engineering faculty member founded and developed a thermal engineering laboratory, in a small liberal arts university. Over the years the faculty member used the students' laboratory fees that varied from \$300 to less than \$1000 a year for small projects involving undergraduate students. Also, that faculty wrote and acquired numerous micro grants for equipment, instruments, and software. These micro grants ranged from $\$ 500$ to $\$ 25,000$. Creative methods were used to create unique hands-on learning opportunities for undergraduate mechanical engineering students. The undergraduate senior students designed, manufactured, assembled, and built unique thermal engineering experiments, with instruction and advising from the author. These activities met numerous of ABET criteria for accrediting undergraduate engineering programs. The projects that were designed and built by the senior mechanical engineering students were used in educating the following cohorts of mechanical engineering students. Many of these thermal projects were published in refereed journals and conferences. The undergraduate students who were involved in these projects ended up being co-authors for the work they were involved with. The total number of publications involving undergraduate students so far is eight refereed articles published in refereed journals and refereed conferences. In addition undergraduate students were co-authors in a poster session. This article details the projects, and the progress of developing the laboratory over sixteen years. Also, the author discusses the environment and settings that help creative development and founding a laboratory, with limited budget, in small universities.
\end{abstract}

\section{Introduction}

The author was employed, as a Mechanical Engineering tenure-track/tenured faculty member for 16 years at Saint Martin’s University, a small, religious, private, Liberal Arts University. The author joined Saint Martin's University immediately after the University celebrated the first century since it was established. There were two undergraduate engineering programs. The Civil Engineering Program was long established, while the recent Mechanical Engineering Program, was accredited five years before the author joined the University. Saint Martin's University has been established on a beautiful wooded area, in addition safety in a small town setting, low cost of living, and the friendly caring environment, were incentives for stability of the faculty in spite of the relatively low salaries.

Over the 16 years that the author was employed at Saint Martin's University the student enrollment in the University grew from less than 1000 students to around 1500 students. While 
faculty growth was approximately $34 \%$, i.e. the total number of full time faculty reached around 100. The first few years, of the author's employment, the budgets for Goods and Services were frozen every April, due to lack of budget. Then apparently the budget improved, and there were no further freezing of budget. That set the background for all faculty to be frugal with the resources, as a matter of fact many of us used the back side of used paper to scribble on to save paper. When faculty or staff left an empty room we turned the lights off to save energy and money for the university. Consequently, asking for a budget for equipment was not an option. This background led the author to think of alternative methods for funding equipment.

\section{Need for a Thermal Engineering Laboratory}

"The laboratory is the means of teaching the experimental method. It should give the student the opportunity to observe phenomena and seek explanations, to test theories and note contradictions, to devise experiments which will yield essential data, and to interpret results."

Cirenza et $\mathrm{al}^{2}$ studied the effectiveness of hands-on, challenge-based workshops to improve junior-level heat transfer students' conceptual understanding of heat and temperature. They compared two groups of students, normal instruction and hands-on, challenge-based workshops. The addition of hands on workshops helped the students to improve on their understanding of the concepts, compared to traditional learning without the hands-on experiments. Thus, based on Bloom's Taxonomy of Educational Objectivs ${ }^{3}$, laboratories help students reach higher levels with two educational goals. Knowledge based goal, where students are able to fully comprehend the abstract concepts introduced in heat transfer, then analyze, synthesis, and evaluate experimental data. Which also contributes to the skills goals of complex overt response, adaptation and organization.

There is no controversy about the necessity of laboratories to support instruction in the Thermal area. Different faculty have experimented with different methods, for example Mativo and Smith ${ }^{4}$ experimented with the unstructured/open approach in Thermo-fluids laboratory.

\section{Founding of the Thermal Engineering Laboratory}

When the author joined Saint Martin's University, the Manufacturing Laboratory was located in a large room in the Facilities building. In a corner of the Manufacturing Laboratory, there were two heat transfer equipment (conduction and convection), both were functioning properly. Though neither the Heat Transfer nor the Thermodynamics courses had any laboratories affiliated with them. The author had the students enrolled in the Heat Transfer course perform experiments outside of the class time, each experiment took approximately three hours. The students expressed that the experiments took too much time out of class. The Chair/Dean supported the author in adding a one credit laboratory to the Heat Transfer course, to meet once for 3 hour/week. Thus, the Thermal Engineering Laboratory started after going through the university channels for approval of adding a laboratory to the Heat Transfer course. 
Two commercial pieces of equipment were already in the Thermal Engineering Laboratory. The conduction apparatus was used to demonstrate two experiments axial and radial conduction. Also, the convection apparatus was used to demonstrate three experiments natural convection, forced convection, and fins. These were only five experiments, i.e. five laboratory sessions out of 14 weeks in the semester. The first offering, the remaining nine laboratory sessions were used for heat transfer numerical projects using Excel, and solving heat transfer problems.

\section{Laboratory Fees}

Engineering and Science laboratory fees were approximately \$35/student/ laboratory, then in later years increased to $\$ 70 /$ student /laboratory. Every year the author counted the number of students enrolled in the Heat Transfer Laboratory, then multiplied the number of students by the laboratory fees, the total ranged from $\$ 300$ to approximately $\$ 1000$. This money was used to fund projects and purchase the following equipment:

1. Thermocouple spot welder, crimping tool box, and thermocouple wire. Students learned to weld thermocouple wires and use thermocouples in projects.

2. Barometer, beakers, stands, portable hot plates, ice trays, and thermoses. These were used as an inexpensive experiment to calibrate thermocouples using the freezing and boiling points of distilled water.

3. Other parts in support of projects given to students.

4. Inexpensive computers, through the Information Technology Department, to be attached to projects.

5. In later years, small miscellaneous parts to support future projects.

\section{Grants}

Saint Martin’s University was so small that there were no rigid policies for grants, this made it easy to submit proposals for small grants which translated in receiving grants in the range of $\$ 500$ to $\$ 25,000$. On the other hand, there was no help with acquiring large grants. Though for a small undergraduate program receiving small grants is easier to handle and absorb.

The author wrote numerous grants for equipment, instruments, and software. Software grants that were used for the thermal modeling course, or heating, ventilating and air conditioning instruction, or grants for creating instructional animations will not be discussed as these are not related to the creation of the laboratory. Also, grants that were for projects ${ }^{5,6}$ that did not contribute to the laboratory equipment will not be included.

Over the sixteen years of the author's tenure, approximately $\$ 60,000$ were received in grants for instruments from Fluke Corporation through the university. In addition to two high end thermal cameras. The instruments varied from dual input thermometers, different types of thermocouple 
probes including immersion, and flat surface, to pressure and temperature calibrators, multimeters, humidity meters, different types of infrared thermometers. With numerous sets of each instrument every student had the chance to practice with the different instruments.

Other grants were received for specific project apparatus, these will be discussed under the heading undergraduate designed, manufactured and assembled projects.

\section{Expansion of the Thermal Engineering Laboratory over Sixteen Years}

The Thermal Engineering Laboratory started as a small corner in the Manufacturing Laboratory, with two pieces of equipment: conduction and convection. Over time the number of equipment started to increase, the laboratory moved to a room, less than 500 square feet, next to the Manufacturing Laboratory.

A few years latter a classroom building was built, which meant relief for classroom space. With the expansion in the number of thermal engineering equipment and the space vacated in the old engineering building, the Laboratory was moved to a thousand square feet classroom, in the old engineering building.

A new engineering building was completed a year before the author moved out of state to another university. The new Thermal Engineering Laboratory in the new engineering building is two thousand square feet, to account for future expansion. Thus, part of the Thermal Engineering Laboratory was used for instruction, as seen in figure 1.

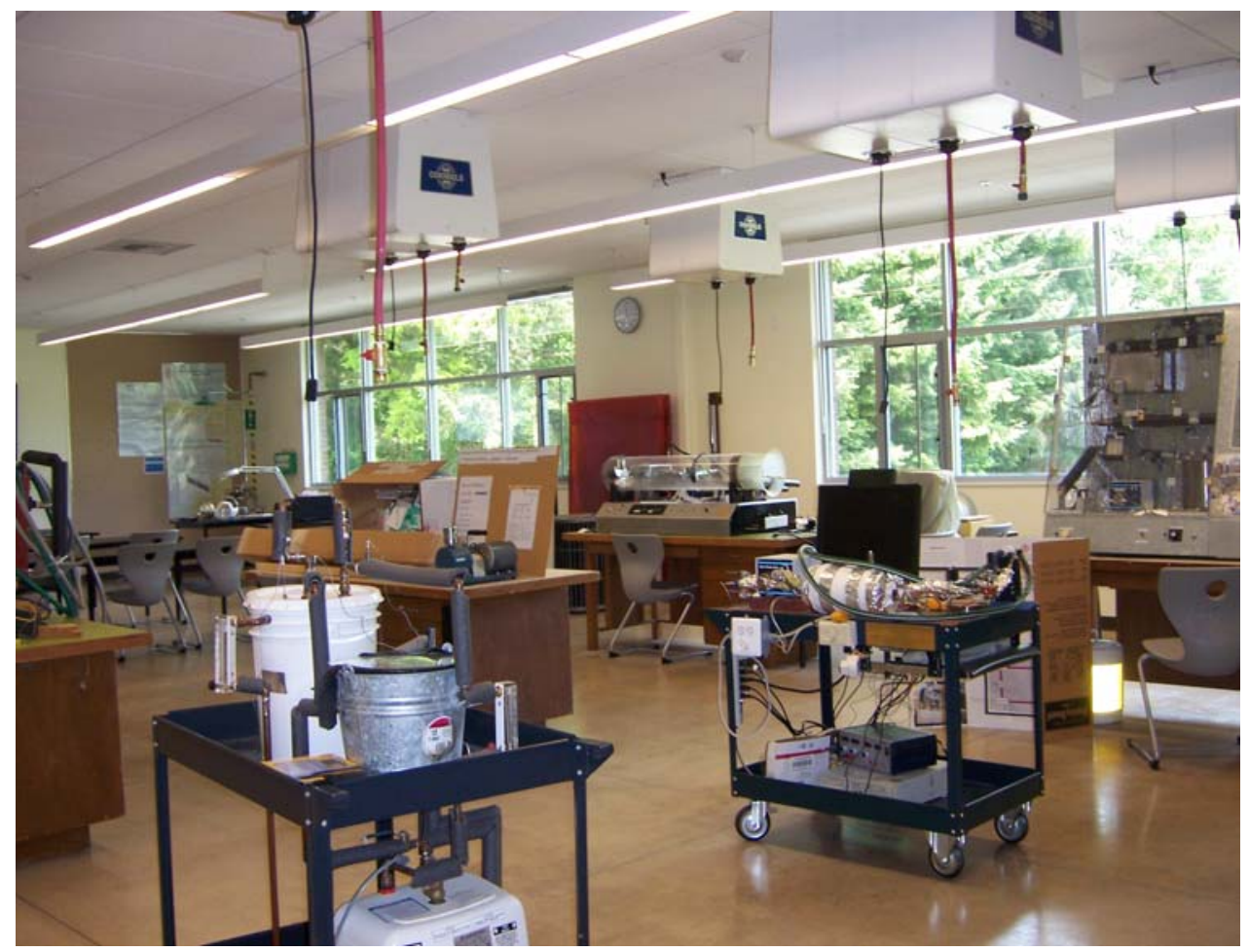

Figure 1: Thermal Engineering Laboratory in the new Engineering building. 


\section{Undergraduate Designed, Manufactured, and Assembled Projects}

Conducting and assessing a senior capstone design course in a small university setting has its challenges. The project is very limited by the amount of resources available, both in terms of finance and in expertise. At the same time, the students must be exposed to the real world with customer-defined constraints, budgetary controls, and time limitations.

Despite budget constraints, the author set up the Thermal Engineering Laboratory at a small liberal arts university. Heat Transfer Laboratory fees were used for projects that supported Thermal Engineering courses. Also, the author has been successful in obtaining grants to create unique, hands-on learning opportunities for Mechanical Engineering Senior Capstone Design I and II students. It should be noted that the Capstone Design courses have a total of 6 credits offered over the fall and spring semesters. At the end of the fall semester senior students complete the design report, which includes: literature searches, detailed calculations, sizing, based on these calculations, engineering drawings, market searches, decision matrices for each part, and detailed budget, within the budget constraints given to the students. Then, before leaving for the Christmas break, the senior students order the parts needed. When the senior students return they find the parts ordered waiting for them. During the spring semester the senior students assemble, manufacture, test their apparatus, trouble shoot problems, collect and analyze the data; more information about the conduct of Capstone Design can be found in reference 7 . In this section projects that resulted in addition of equipment to the Thermal Engineering Laboratory will be discussed, whether published or not. It should be noted that all published projects were published in refereed venues (journals and conferences), and were coauthored with undergraduate students. On the other hand, projects that were co-authored with students but did not contribute to addition of equipment to the Laboratory, or were not conducted at this University will not be discussed ${ }^{5,6 \text {, and } 8 .}$

\section{Shell and Tube Heat Exchanger Experiment}

One shell and four tube passes small heat exchanger was acquired from Boeing Company surplus. The shell and tube heat exchanger was dismantled and cleaned. Eight students were enrolled in the Heat Exchanger course, they were asked to design an experiment based on the shell and tube heat exchanger available. The class was divided in two teams, each team presented their design (including detailed calculations) at the middle of the semester. The second half of the semester both teams were combined, and the feasible ideas submitted by both teams were used for the final design that was assembled and built. The heat exchanger experiment is shown in figure 2. This project was funded from student fees for the Heat Transfer Laboratory. Ever since, with every offering of the Heat Transfer course, students performed the Shell and Tube Heat Exchanger Experiment. The laboratory handout as well as the pictures hanging behind the apparatus show pictures of the various parts of the one shell four pass heat exchanger experiment. The students are given the tube size as 16 BWG and asked to estimate the internal dimensions of the heat exchanger, based on measurements of external dimensions, 
the given pictures, and their calculations. The students estimate the heat transfer area, fouling factors, then they estimate the overall heat transfer coefficient theoretically and experimentally, using both the logarithmic mean temperature and number of transfer methods. Finally, the students discuss any deviations between experimental and theoretical predictions.

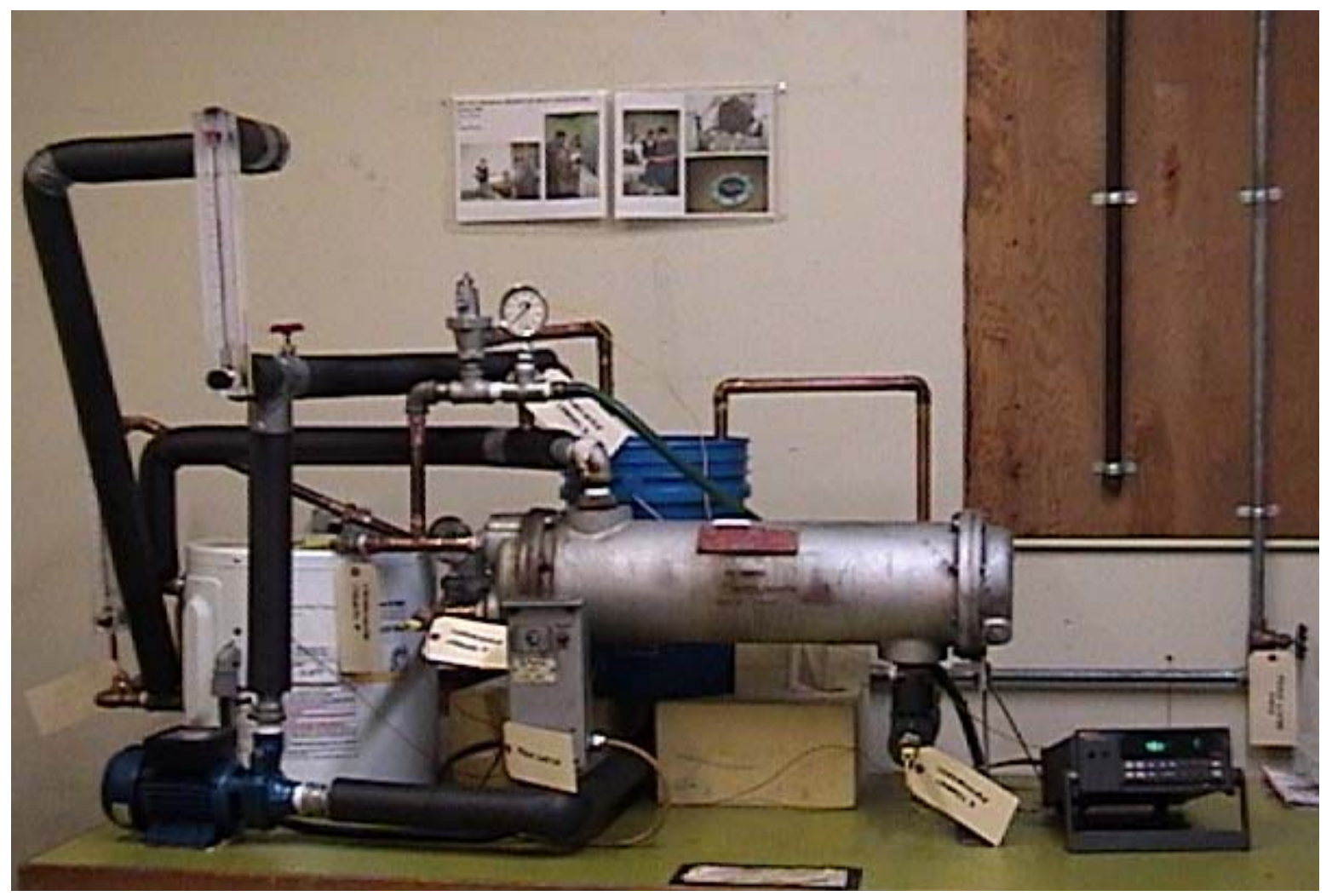

Figure 2: Shell and tube heat exchanger experiment.

\section{Instrumented Heating, Ventilating, and Air Conditioning Experiments ${ }^{9}$}

A Senior Capstone Design Team was asked to design and build a bench-top air conditioning experiment to be used in a laboratory setting at the Thermal Engineering Laboratory. The cost of all the components including instrumentation and data acquisition was limited to less than $\$ 6000$; this last specification was based on the amount of \$5,000 grant from the American Society of Heating, Refrigeration, and Air Conditioning Engineers (ASHRAE), in addition to $\$ 1000$ allocated by the department for every senior capstone design project. A unique, safe air conditioning/refrigeration bench experimental apparatus, was designed, manufactured, and assembled, shown in figure 3. This system demonstrates the fundamentals of the refrigeration cycle and psychrometric properties of air, as well as some fundamental concepts in heat transfer, heat exchangers, and thermodynamics. The apparatus is equipped with an instrumentation package to monitor the psychrometric properties of the air inside the transparent ductwork and the working fluid properties via computerized data logging equipment. It is worth noting that a market survey revealed that commercially available systems tend to be large, some being up to 
seven feet tall and weighing hundreds of pounds, and none of these equipment perform or have all the functions, nor the data acquisition system programmed by the students. These commercial training systems reached up to $\$ 60,000{ }^{9}$. The apparatus has been used consistently to support instruction in four thermal engineering courses. More information about the apparatus and the experiments that can be performed can be found in reference 9 .

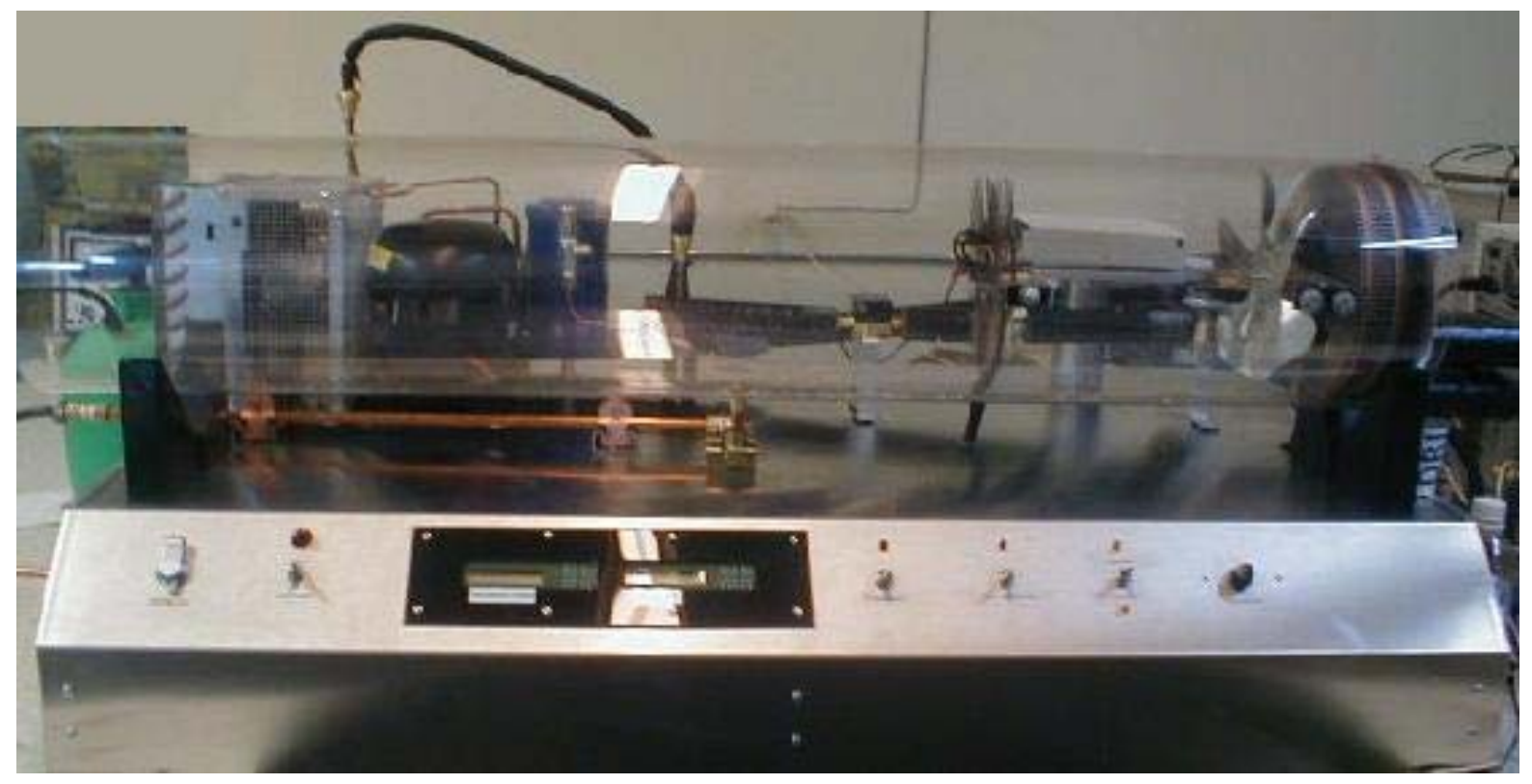

Figure 3: Instrumented heating, ventilating, and air conditioning experiments.

\section{An Experimental Unique Absorption Refrigeration Cycle ${ }^{10,11}$}

This project was also supported by a \$5000 ASHRAE grant to the author in addition to the normal \$1000 allocated by the department for every Mechanical Engineering Capstone Design. In commercial applications aqueous solutions of lithium bromide and water, or ammonia and water are used as the working fluids. An investigational absorption cycle, shown in figure 4, was designed, manufactured and constructed. Non-traditional absorbent/refrigerant pairs were investigated and the selected working fluids were aqueous ethylene glycol/water. The working fluids selected are safe, unlike the commercial absorbent/refrigerant pairs, and in contrast to lithium bromide does not crystalize, i.e. less operational problems. The coefficient of performance for the aqueous ethylene glycol is 0.67 for refrigeration, which is higher than ammonia/ammonium hydroxide's COPR of 0.5 , though comparable to the lower range of the $\mathrm{COP}_{\mathrm{R}}$ for aqueous $\mathrm{LiBr} /$ water absorption cycles ${ }^{10,11}$. This apparatus is used to measure temperatures, pressures, and flow rates of the working fluids, then determine the various thermodynamic properties for each stream, the rate of heat transfer, work input, and coefficient of performance. The apparatus aided in the instruction of four thermal engineering courses: Heat Transfer, Thermodynamics, Heating Ventilating and Air Conditioning, and Energy Systems. 


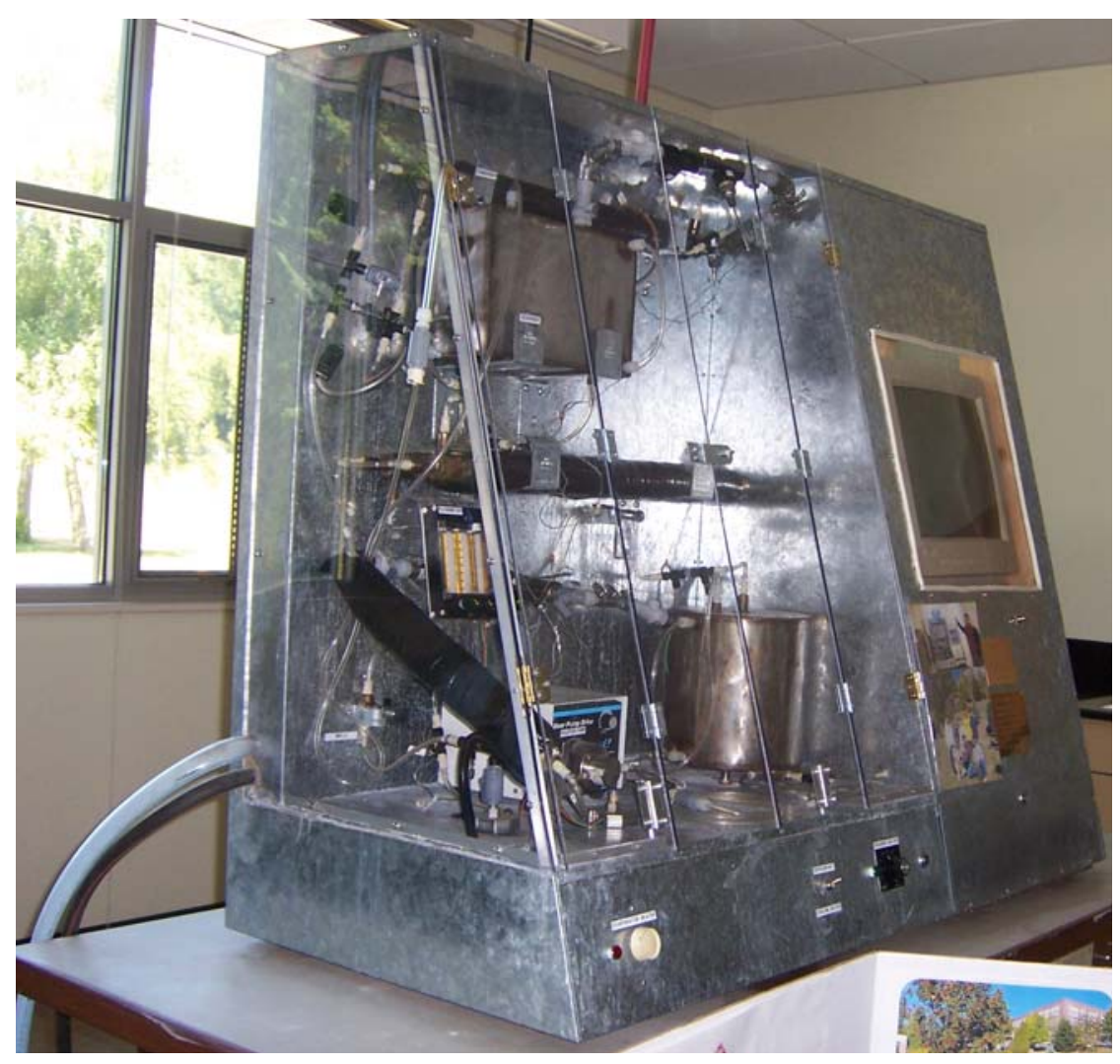

Figure 4: An Experimental Unique Absorption Refrigeration Cycle.

\section{Helical Coil Heat Exchanger Experiment ${ }^{12}$}

The Manufacturing Laboratory Technician acquired a helical coil, shown in figure 5, from Boeing's surplus and gave it to the author.

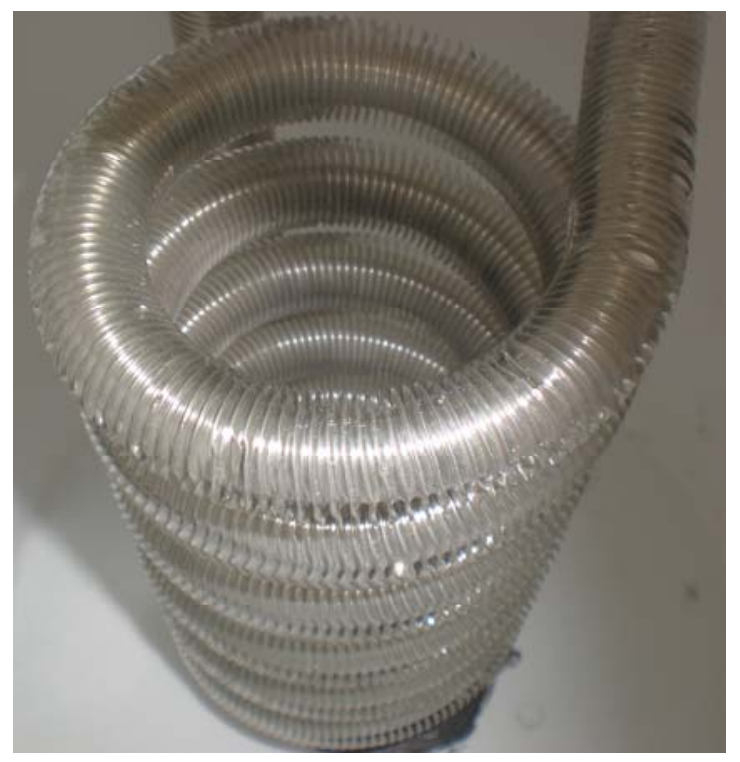

Figure 5: Helical coil used in the heat exchanger experiment. 
The enhanced helical coil was given to the students enrolled in the Heat Exchanger course. In addition to course work the students designed and assembled the experiment. A limited budget, based on Heat Transfer Laboratory fees, was assigned for this project. Due to the limited budget buckets were used as containers and shell for the heat exchanger, as seen in figure 6 . The apparatus has been consistently used as an additional heat transfer experiment in the Thermal Engineering Laboratory. A sample experimental run is given in reference 12.

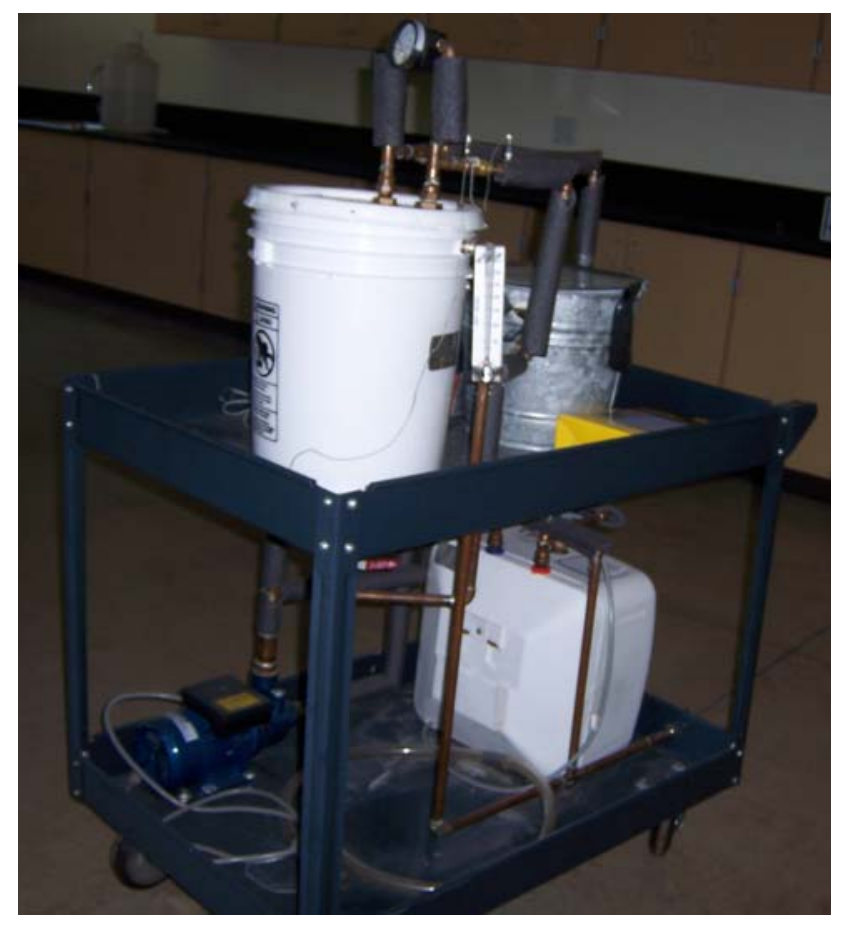

Figure 6: Helical coil heat exchanger experiment.

\section{Instrumented Instructional Small Scale Rankine Vapor Power Cycle ${ }^{13}$}

There are several commercial laboratory experimental apparatus available; unfortunately most of these apparatus are not closed Rankine cycles. Only one commercial educational assembly was found that met the criteria of a closed-loop vapor power cycle utilizing a turbine and an instrumentation package, but the high cost (approximately $\$ 130,300$ ) made it unfeasible for acquisition ${ }^{13}$. This unique project was assigned to a capstone design team. It was funded by the normal \$1000 dollar allocated by the Mechanical Engineering Department, and funds remaining from previous grants. As usual, the project was successful in meeting all the requirements including: utilization of the limited space in the Thermal Engineering Laboratory, budget constraints, and safety. The lower pressure of the cycle can be kept at $101 \mathrm{kPa}$, while the higher pressure can be varied, though it is recommend to keep it below $240 \mathrm{kPa}^{13}$. Control and immediate visual feedback is provided for the boiler heating element, the superheater, and the pump. The power output of the turbine is made visible by connection of the generator to lighting elements. Efficiency of the cycle is low in exchange for the necessary safety of an 
undergraduate experiment that will continue to be used to supplement the instruction of four thermal engineering courses. Reference 13 gives a sample experimental run, with calculations. The Rankin cycle connected to the data acquisition is shown in figure 7.

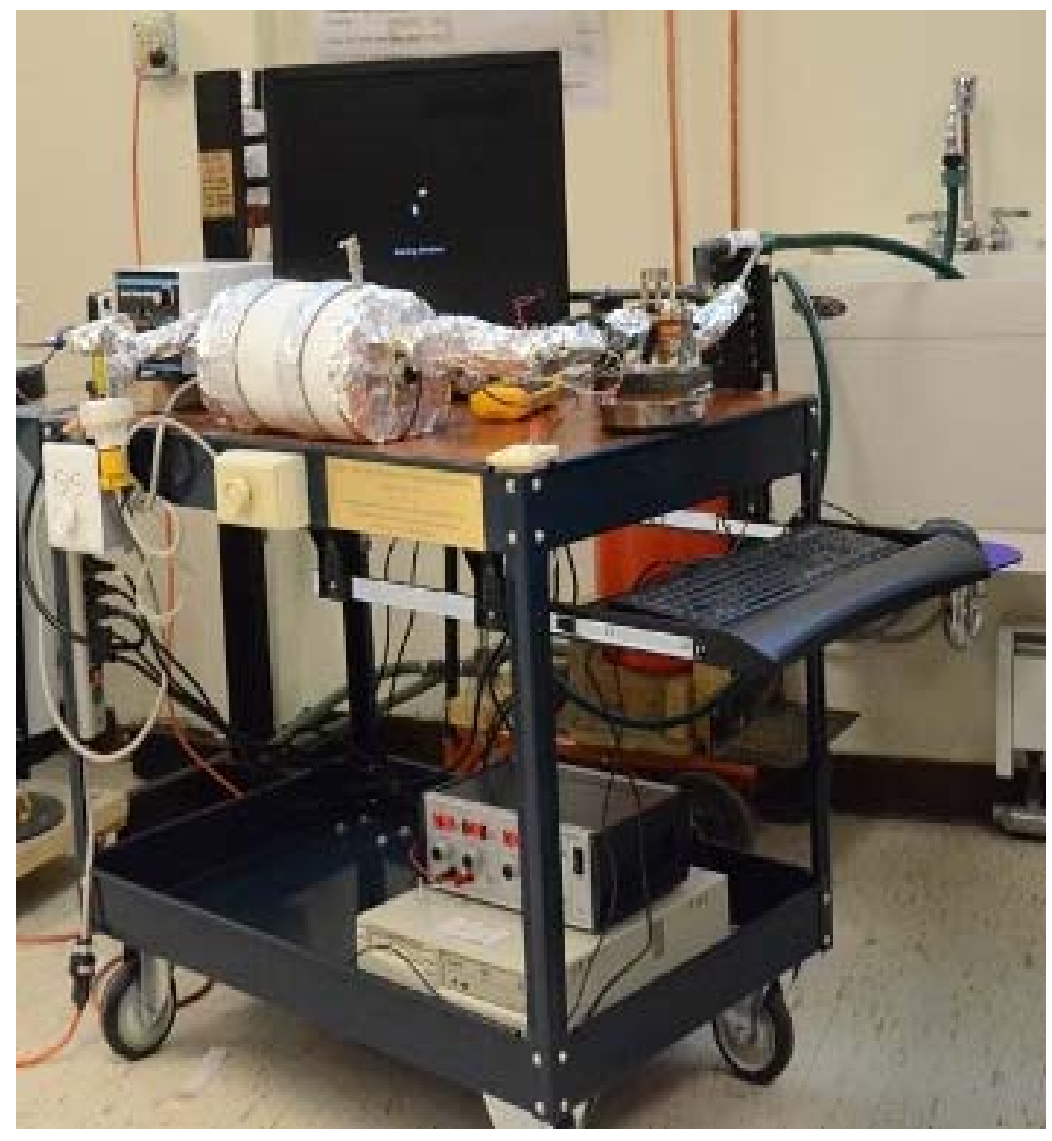

Figure 7: Instrumented Rankin cycle experiment.

\section{Heat Flux Simulator}

The National Aeronautics and Space Administration (NASA) supported this project with a $\$ 25,000$ grant. When designing space vehicles it is essential to account for the ability of the materials to withstand the extreme high temperatures associated with hypersonic flight during reentry. For this reason, the Flight Laboratory at NASA's research center needed equipment to test various materials' reaction to these tremendously high temperatures and heat fluxes. A heat flux simulator, shown in figure 8 , was designed and built to simulate high-temperature, using heat sources. One to four quartz lamp sets can be mounted. When mounting four quartz lamp sets, the operator should have the choice of different arrangements, for example: rectangular, staggered (like laying brick), or parallel. A tray with heat flux gages was set under the heating quartz lamps. After comparing the properties of different materials a tray material that does not buckle under heat was chosen. The heat flux gauge, the quartz lamp sets have the capability of moving in three dimensions. That means that the distance between the heat flux gage and the quartz lamps can be adjusted, as well as the planar distances. The heat flux gage have the 
capability of moving slowly continuously for accumulation of data under different locations from the quartz lamps. The data acquisition system (using LabView) can continuously monitor and record: the heat fluxes measured by heat flux gages, the exact special positions relative to the quartz lamp heaters at the time of recording, the power input to the quartz lamps Even though this project was not published, and was shipped to NASA after completion, one of the students from the team spent a summer at NASA reassembling and operating the project.

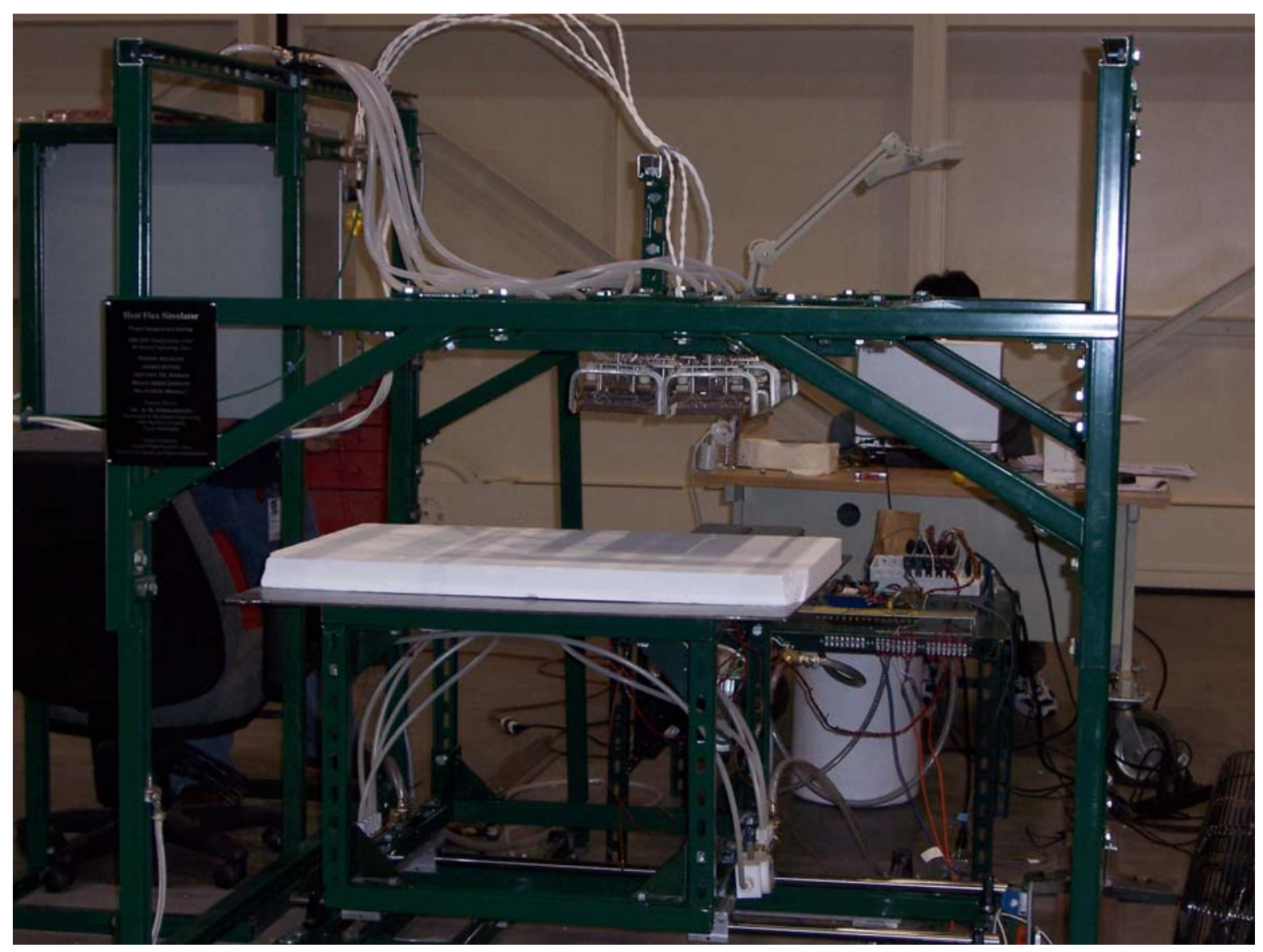

Figure 8: Heat flux simulator.

\section{Thermal Imaging of Photovoltaic Tracking Array ${ }^{14}$}

This project utilized photovoltaic solar panels that were installed on the roof of the new engineering building. This project was conducted as part of the requirements for the Solar Thermal Engineering course, where students learned about photovoltaic solar systems, and the building supplied the experimental tools. In addition to the course material the students performed literature searches, collected data, and compared data with theoretical expected data. Figure 9 shows the thermal imaging and analysis of the solar photovoltaic solar panel. The project was displayed as a poster at a Heat Transfer Conference ${ }^{14}$. 


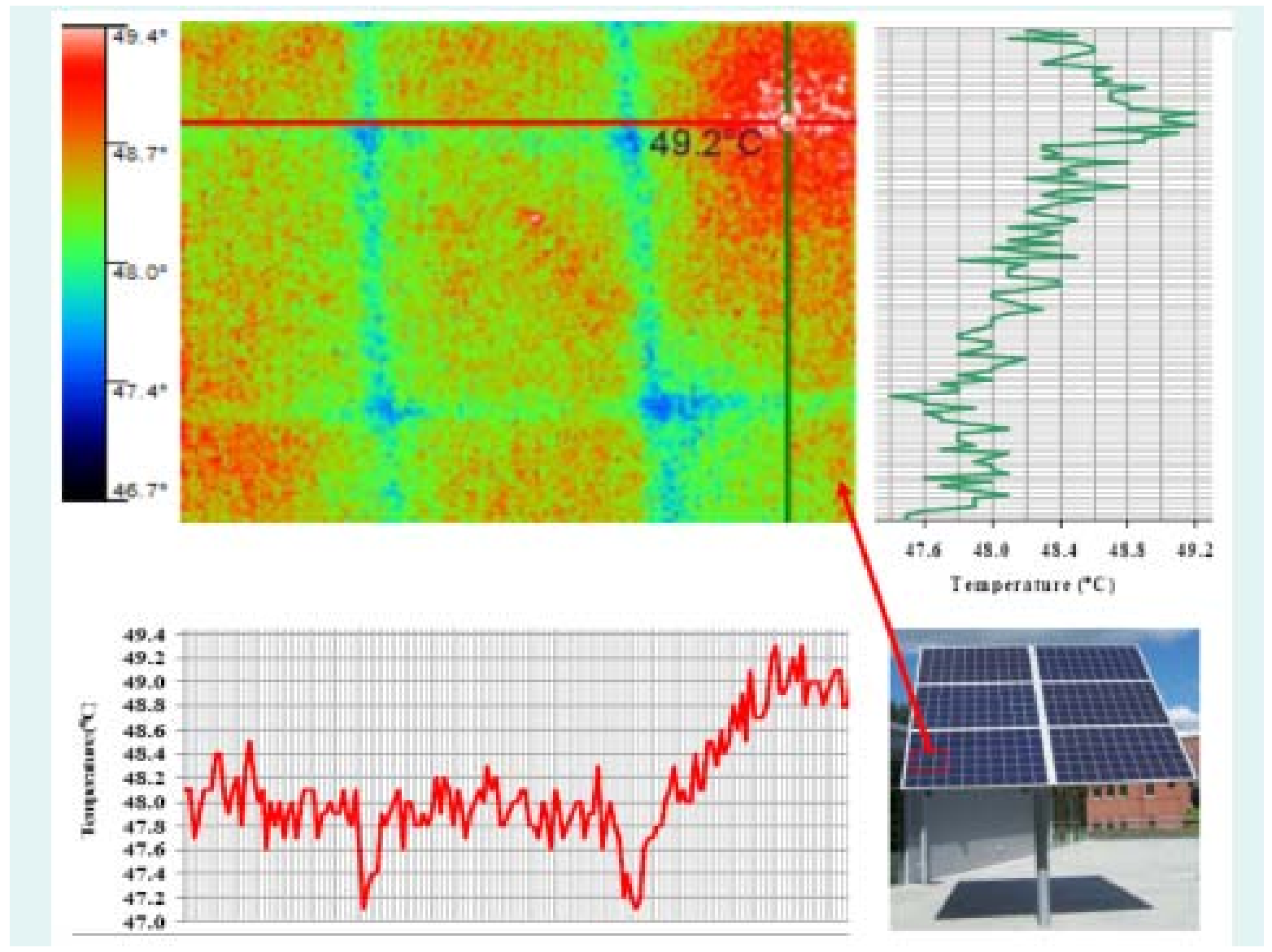

Figure 9: Thermal Imaging of Photovoltaic Tracking Array ${ }^{14}$.

\section{Assessment}

In order to expand the students' exposure to the practical application of knowledge and to utilize their creativity, open-ended design-build projects were used which required the students to use creative approaches in order to find solutions to the given problems, with several constraints, from design objectives, limited space, and small budget. Consequently, a full-cycle of learning experience took place that involved solving real problems. This began with handing the team a statement of the unique practical project, continued through with literature and market searches concurrent with the design, and submitting a report of preliminary design to an invited panel of engineers, and presenting their work to the panel. Then followed, the next semester, with construction of a working apparatus, managing limited budget, space constraints, and concluded by writing a detailed report and an oral formal presentation to the engineering panel. At the end of each semester each member of the external engineering panel was provided a detailed report, a few days before the students presented their project. The members of the engineering panel were specialized in the area of the project, e.g. NASA engineers flew in for the Heat Flux Simulator, while HVAC engineers served as panelists for the Instrumented Heating, Ventilating, and Air 
Conditioning Experiments and the Absorption Refrigeration Cycle. Twenty percent of a team's grade was based on the panel evaluation, which was consistently positive.

\section{The Following ABET ${ }^{15}$ Student Outcomes have been met through the Capstone Design}

\section{(a) An ability to apply knowledge of mathematics, science, and engineering}

In each of the design-build projects Fluid Mechanics theories were employed in calculations for pressure drop, and pump sizing. Heat Transfer concepts were used for the design of the heat exchangers, condenser, boilers, absorbers, desorbers, and other heat transfer equipment. Knowledge from Materials Science and Chemistry helped in identifying the corrosion possibilities with the choice of materials. Skills learned from Manufacturing Processes were used in manufacturing several parts of each apparatus. Concepts from Statics, Dynamics, and Mechanics of Materials helped in calculations of the stresses in the system particularly the boiler, and designing adequately. Not to mention that the concepts from Thermodynamics were used extensively in most of these projects. A specific example that was not previously published is the course skills the students learned during the senior design of the Heat Flux Simulator: Heat Transfer (radiation from lamps to target, thermocouples, heat flux gages, and cooling systems), Fluids (choice of piping and specification of pipes, and friction), Materials Science and Chemistry (to choose materials of construction, corrosion, and flammability of components) Dynamics, Statics, Mechanics of Materials , and Manufacturing (for construction and design of support truss system), Controls, and Instrumentation to manage the actuators and data acquisition. Students performed calculations and CAD (solid work) drawings of the design. In addition students learned how to use Lab View on their own.

\section{(b) An ability to design and conduct experiments, as well as to analyze and interpret data}

Students designed and built an apparatus that met the specifications given to them, tested the apparatus, collected data, and analyzed the data. They were able to meet the safety, budget, time, and space constraints in each of these designs.

(c) An ability to design a system, component, or process to meet desired needs within realistic constraints such as economic, environmental, social, political, ethical, health and safety, manufacturability, and sustainability

Students were able to meet the safety, budget, time, and space constraints, in each project. They examined codes and checked EPA regulations. They manufactured several parts and made several modifications to some purchased parts. Students contacted different companies for parts and discussed the various aspects, constructed decision matrices, before ordering the parts.

\section{(d) An ability to function on multidisciplinary teams}

Students learn early in the program to work in teams, in almost all Mechanical Engineering courses. Usually, by the senior year the students know how to work well in a team setting. 
Students formed small teams to tackle different aspects of the project and became specialized in those aspects. The faculty advisor was impressed with the team spirit shown by the students working together. The advisor was particularly impressed with those students who continued to work with the advisor after graduation, without pay; even though most of them were working and had to deal with family issues. Those students only reward was co-authorship of refereed published articles.

\section{(e) An ability to identify, formulate, and solve engineering problems}

Numerous problems were encountered in each project. Some of the problems were due to issues expected or not expected, these problems were later solved. Sometimes the problems lead to innovative solutions, and calculations. Details of these problems are given in the open literature for two of the projects: the helical coil experiment ${ }^{12}$ and the Rankin cycle experiment ${ }^{13}$.

\section{(f) An understanding of professional and ethical responsibility}

Each semester of the capstone design courses there was an ethics lecture. All the teams, the author worked with, were self-motivated and met all their deadlines. After the students graduated, grades were submitted, and students got jobs, some of the team members still kept pushing for publishing. Students were professional in dealing with each other, faculty, and other contacts. In addition, students were professional in responding to e-mails and keeping all team members and faculty updated.

\section{(g) An ability to communicate effectively}

Oral, written, and professional communication have been stressed and practiced. Oral communication skills were advanced by means of giving presentations to various demographic groups. These presentations also varied in terms of style. There were frequent informal in-class and out-of-class updates to the faculty advisor and classmates, more formal technical presentations to faculty and a professional engineering panel at the end of each semester, and the more laid-back 'show and tell' style manned display at the Engineering banquet. Each team elected a member to submit the team's abstract to the Scholar's Day Committee and to serve as liaison on the team's behalf. Scholar's Day is held at the end of the spring semester, and a few outstanding projects selected from all disciplines in the university are presented. The students had the opportunity to improve their public speaking abilities at the Scholar's Day event, where the presentations were for a non-technical audience. As to technical writing skills the team submitted a formal report at the end of each semester and most of them are co-authors for technical articles related to the projects they worked on. Not to mention they communicated with different vendors for the various parts purchased for the apparatus. Also, students practiced communicating with each other, the faculty advisor, and the vendors by e-mail. Each student documented his/her activities on these projects through logbooks. 


\section{(h) A recognition of the need for, and an ability to engage in life-long learning}

The teams performed literature and market searches. The University did not have LabView, thus from each capstone design team several team members attended workshops on LabView, and programmed LabView to monitor and acquire data. Each of the capstone design projects acquired a LabView license from the project budget, which was used for data acquisition.

\section{(k) An ability to use the techniques, skills, and modern engineering tools necessary for engineering practice.}

The students programmed LabView to operate the designed and built apparatus, they also used CAD and Solid works for representing the different components and to generate animations. Furthermore, students used software to form a mathematical model of their system. Students used different equipment for manufacturing various parts or modifying parts.

Student comments on the helical coil experiment project ${ }^{12}$ and the Rankin cycle experiment ${ }^{13}$ are published in the open literature.

We were unable to use the Fundamentals of Engineering (FE) Exam to access the performance of the students in the area of Heat Transfer due to several factors. The number of graduating Mechanical Engineering students was usually less than 20 students and never exceeded 26. Few students took the FE, and fewer of those students elected the Mechanical Engineering Fundamentals of Engineering Exam, rather than the General Exam. In two of the latter exams only one student took the FE Mechanical Engineering the results of the two students in the thermal area were 67 and 78 compared to 60 , and 45 for the national average, respectively. A second problem is that these results do not distinguish between Thermodynamics performance and Heat Transfer performance. The third problem is that after these results no further FE results were shared with the author.

\section{Environment and Settings that help Creative Development by Faculty}

\section{Sense of Job Security and Belonging helps Creativity}

There was a sense of job security and belonging. The first indication of that sense of security was that every April, the first few years of the author's employment, the Goods and Services budgets were frozen, all over the university, due to lack of budget. To the author's knowledge no one lost a job, during those times. Staff and faculty were not worried about losing their jobs. The second indication was 'Goodbye Parties' were a common practice to even staff, who were employed for a short period, and left for higher paying jobs. The third indication, was everyone was trying to save money for the University. There was an unwritten or stated culture of trying to save money for the university. Shortly, after employment the author noticed that colleagues turned off unused lights and used back of used paper for scribbling, to save money, and of course the author copied the behavior. 
All through the University there was a sense of caring about faculty, staff, and students. When a staff member had a long illness, other staff members donated their vacation time to be used by the sick staff. When a faculty was sick for an extended period, other faculty volunteered to cover the sick faculty member classes. Also, management was compassionate and tried to help faculty and staff.

After the financial market crash of 2008, where many universities were affected, some universities closed their doors. The president announced that the university is in financial distress and either cut the university contribution to the retirement plan or layoff, new faculty. The tenured faculty elected to cut the pension plan, which was latter restored in full.

\section{Management}

Type of management reflects directly on the Dean, and Chair, but could also be a reflection of Provost and President's policies. Micromanagement and too many rules can hinder any creativity or progress. An incompetent manager, who says no just to show his/her command, loses the respect of the faculty, and their enthusiasm. The Chair/Dean must be supportive, by supportive does not mean give sweet vague words, with no real support. Support needs to be by action, and fighting for his/her faculty, where it counts, not by the manager's account. Most of the tenure of the author at that University, there was a visionary, compassionate Dean/Chair who was supportive. The Dean/Chair had an open door policy, and was always willing to give good advice on how to handle nontechnical hurdles, and many times was willing to give more financial help when the budget allowed.

Supportive chair and dean, even with limited budget, is a great asset. Micro managing middle administration can be a complete hurdle to any progress, or even daily simple functioning. Jenkins ${ }^{16}$ wrote an article about the traits of a good academic manager that can be consulted for more characteristics.

\section{Reasonable Teaching Loads}

Liberal arts universities require varying teaching loads. Some require as high as 24 credits/ academic year even for engineering faculty. Though other universities recognize that high loads are not conductive to Engineering Education and require 18 credits/ academic year.

When faculty teach the courses they are specialized in and enjoy, that enhances the feelings of satisfaction and lead to creativity. Happy faculty go out of their way to help students succeed.

\section{Rules and Regulations}

Every university has its own set of rules and regulations, related to every aspect of university functioning. Usually, large research oriented universities research rules are well spelled out, and faculty get training, and help. While small Universities do not have the budgets to support research or even developing these rules. It helps the new faculty to have the existing rules and 
regulations spelled out, and easy to go back to check the rules. Most Universities hand new faculty a hard copy of the 'Faculty Handbook,' and a hard copy of the current 'University Catalog.'

An example of rules: The University had a system that any purchase had to be signed by the faculty member, followed by department chair, then by the dean, afterwards by the vice president of academic affairs before it goes to the finance office for issuing a purchase order. The chair/dean signed immediately, but the vice president signed only once a week, and if the vice president is out of town or too busy then the process is delayed. This process took from two to four weeks, i.e. too much time for projects to be completed. After the first grant, the author negotiated that for grants she acquired, only her signature would be require. Ever since purchase orders took from one to three days, i.e. time was saved for student projects.

\section{Students}

Every student is different in personality, what the student values most, levels of motivation, ethics, and personal circumstances. With that in mind there are sometimes various situations that can arise in a capstone design project. For example one student cares only to get the minimum to pass the course, while another will not settle for less than a grade of $\mathrm{A}+$. Another high scoring student realizes that the grade for capstone design is a team grade, so decides to invest study time for other courses. These are some of the issues the capstone design advisor will have to find ways of handling.

From the author's experience, projects related to a course, students will invest time, because the student needs a grade to graduate. But paid undergraduate research or work-study summer projects are not always conductive. The reason is students prefer internships in a company, even if it pay less, because the company may employ them and they experience industry.

Some engineering students have high integrity and are perfectionists, that they continue working on a project after they receive grades for the course.

\section{Faculty Advisor}

The faculty advisor must be enthusiastic about the given project. For every project the author has spent extensive time with the students. Before assigning any project the author has a certain idea and expectations. But the students were left to come with their own ideas based on their strengths. Most of the projects came out much better than the author expected. The author works with the students based on their strengths, and the ideas they come up with after brain storming, checks every detail of their work, including the literature searches they perform and makes sure that the students got out of it the important information. Every piece of calculation is checked, and questions about other calculations that should be performed. It should be noted that most students want to purchase and assemble parts without calculations. Before approval for purchases, a decision matrix has to be shown to the advisor, and good justification for the 
reason for the purchase, and pertinent calculations must be submitted. Mistakes are allowed, as this is a learning process. It should be noted that advising a single project takes more time than preparing a new course, but the accomplishment of the students is rewarding.

\section{Founding and Funding an Engineering Laboratory is Possible to Recreate}

About three years ago, before the date of this publication, the author moved to California Baptist University, a larger Religious, Liberal Arts University, in a different state. The College of Engineering was founded a few years ago, and due to a visionary Dean grew extensively in programs, enrollments and faculty. The Mechanical Engineering program in the new University was accredited 2010. The author is trying to recreate and develop a Heat Transfer Laboratory. Rules and regulations are completely different in the new University. Laboratory budget is higher than the previous University, though due to the quick expansion of the University, from the author's experience purchase orders take a month and half from date of request to be ready for ordering. Colleagues were ingenious in handling this problem by having orders done on line through four distributors, vetted by the university. This system seems to cover many items, unfortunately it does not cover unique items. The new University has rules and regulations about asking for grants or equipment from outside. Which translates to more difficulty in getting small grants, but one needs to understand the system better, to be able to function efficiently.

Student culture differs from one university to the other, even over the years in the same university student culture changes. The first year the author joined the new University, the author had difficulty understanding, and thus navigating the system. The second year the author started trying to navigate the system, and making minor changes to the student culture, starting by inviting the juniors to the senior presentations, which resulted in more enthusiasm by the third year for the capstone projects. Currently, a capstone design team is working with the author on an interesting project that will be a new apparatus in the Heat Transfer Laboratory. With time and better understanding of all rules and regulations, all hurdles can be overcome and creation of a dream laboratory can be accomplished.

\section{Bibliography}

(1) Engineering Deans, January 1994, “The-Grinter-Report,” ASEE Journal of Engineering Education, pp. 82.

(2) Cirenza, C., Diller, T., and Williams, C., 2015, “Assessing Effects of Challenge-Based Instruction on Conceptual Understanding In Heat Transfer," $122^{\text {nd }}$ ASEE Annual Conference and Exposition, Seattle, WA. 
(3) http://teaching.uncc.edu/learning-resources/articles-books/best-practice/goals-objectives/bloomseducational-objectives

(4) Mativo, J.M., and Smith, N., 2011, "Learning in Laboratory Compliments to Lecture Courses via Student Designed and Implemented Experiments," ASEE conference proceedings

(5) Abdelmessih, A., and McGuire, E., 2011, "Literature Review of Single Phase Internal Flow Heat Transfer Correlations," published in the proceedings of the ASME/JSME 8th Thermal Engineering Joint Conference, Honolulu, Hawaii.

(6) Abdelmessih, A., N, Beakley, M., Campbell, S., McKnight, E., Roberts, M., and Woodward, E., 2010, "Infrared Electric Emitters for Drying Paper," proceedings of the 14th International Heat Transfer Conference, Washington DC.

(7) Abdelmessih, A., de Sam Lazaro, A., and Jung, I., July 2005 “An Integrated Concept-to-Prototype Capstone Design Experience,” ASEE conference proceedings, Portland.

(8) Hersey, D., Demopoulos, G., Loeffler, B., Tjutarwy, B., LaPoint, S., and Abdelmessih, A., August 1997, “Testing and Thermal Analysis of Multichip Modules," HTD-Vol 343, 32nd National Heat Transfer Conference, ASME Proceedings, v. 5, pp 17-26, Baltimore.

(9) Abdelmessih, A., Dye, Doughty, Heitzmann, Holtcamp, Miller, and Perkins, July 2003, “Instrumented Air Conditioning Bench Experimental Apparatus,” Proceedings Summer Heat Transfer Conference, Nevada.

(10) Abdelmessih, A., with M. Abbas, A. Al-Hashem, and J. Munson, September 2005, “An Experimental Unique Absorption Refrigeration Cycle,” 4th International Conference on Heat Transfer, Fluid Mechanics, and Thermodynamics, Cairo, Egypt.

(11) Abdelmessih, A., N., Abbas, M., Al-Hashem, A., and Munson, J, 2007, "Ethylene Glycol/water as working fluids for an experimental absorption cycle,” Journal of Experimental Heat Transfer, 20:87-102, Taylor \& Francis Group, LLC.

(12) Abdelmessih, A., Cummings, S., Jorgenson, M., Parker, J., July 2009, 'Undergraduate Class Project: Design and Build A Helical Coil Heat Exchanger Experiment’ proceedings of the 2009 Summer Heat Transfer Conference, San Francisco, California.

(13) Abdelmessih, A., Boley, R., Davis, C., de Lima, B, Lobets, D., and Rogge, B., 2012, “Design and Construction of an Instrumented Instructional Small Scale Rankine Vapor Power Cycle by and for Undergraduate Students," published in the proceedings of the 2012 Heat Transfer Conference, Puerto Rico.

(14) Abdelmessih, A., Buehn, J., Ferguson, S., Lawrence, D., and Neilson, B., 2013, 'Thermal Imaging of Photovoltaic Tracking Array,' Poster displayed in session 15.3 Photogallery at the 2013 Heat Transfer Conference, Minneapolis, MN.

(15) ABET, 2001 to 2015, “Criteria For Accrediting Engineering Programs.”

(16) Jenkins, R., 2013“What Makes a Good Leader?” Chronicle of Higher Education, 00095982, Vol. 59, Issue 26. 